\title{
Sample Return Propulsion Technology Development under NASA's ISPT Project
}

\author{
David J. Anderson ${ }^{1}$ (216-433-8709, David.J.Anderson@nasa.gov) \\ John Dankanich² (216-433-5356, John.Dankanich@nasa.gov) \\ David Hahne ${ }^{3}$ (757-864-1162, David.E.Hahne@nasa.gov) \\ Eric Pencil1 (216-977-7433, Eric.J.Pencil@nasa.gov) \\ Todd Peterson'1 (216-433-5350, Todd.T.Peterson@nasa.gov) \\ Michelle M. Munk ${ }^{3}$ (757-864-2314, Michelle.M.Munk@nasa.gov) \\ ${ }^{1}$ NASA Glenn Research Center, 21000 Brookpark Road, Cleveland, OH 44135 \\ ${ }^{2}$ Gray Research, Inc., Cleveland, OH 44135 \\ ${ }^{3}$ NASA Langley Research Center, 1 North Dryden Street, Hampton, VA 23681
}

Abstract-In 2009, the In-Space Propulsion Technology (ISPT) program was tasked to start development of propulsion technologies that would enable future sample return missions. Sample return missions can be quite varied, from collecting and bringing back samples of comets or asteroids, to soil, rocks, or atmosphere from planets or moons. As a result, ISPT's propulsion technology development needs are also broad, and include: 1) Sample Return Propulsion (SRP), 2) Planetary Ascent Vehicles (PAV), 3) Multi-mission technologies for Earth Entry Vehicles (MMEEV), and 4) Systems/mission analysis and tools that focuses on sample return propulsion. The SRP area includes electric propulsion for sample return and low cost Discovery-class missions, and propulsion systems for Earth Return Vehicles (ERV) including transfer stages to the destination. Initially the SRP effort will transition ongoing work on a High-Voltage Hall Accelerator (HIVHAC) thruster into developing a full HIVHAC system. SRP will also leverage recent lightweight propellant-tanks advancements and develop flight-qualified propellant tanks with direct applicability to the Mars Sample Return (MSR) mission and with general applicability to all future planetary spacecraft. ISPT's previous aerocapture efforts will merge with earlier Earth Entry Vehicles developments to form the starting point for the MMEEV effort. The first task under the Planetary Ascent Vehicles (PAV) effort is the development of a Mars Ascent Vehicle (MAV). The new MAV effort will leverage past MAV analysis and technology developments from the Mars Technology Program (MTP) and previous MSR studies. This paper will describe the state of ISPT project's propulsion technology development for future sample return missions. ${ }^{12}$

\footnotetext{
${ }^{1}$ U.S. Government work not protected by U.S. copyright

${ }^{2}$ IEEEAC paper \#1115, Version 3, Updated January 1, 2011
}

\section{TABLE OF CONTENTS}

1. INTRODUCTION .............................................................. 1

2. TECHNOLOGY DEVELOPMENT OVERVIEW ................. 2

3. ELECTRIC PROPULSION FOR SAMPLE RETURN AND DISCOVERY-CLASS MISSIONS ..................................... 2

4. Planetary Ascent Vehicle (PAV)....................... 3

5. PROPUlSION COMPONENT TECHNOLOGIES................ 5

6. MULTI-MisSiON EARTH ENTRY VEHICLE (MMEEV)7

7. SYSTEMS/MISSION ANALYSIS ..................................8

8. Conclusion and Future Plans ................................. 8

ACKNOWLEDGMENTS........................................................9

REFERENCES..........................................................9 9

BIOGRAPHIES................................................................. 10

\section{INTRODUCTION}

NASA's Science Mission Directorate (SMD) missions seek to answer important science questions about our planet, the Solar System and beyond. To meet NASA's future mission needs, the goal of the ISPT project is the development of new enabling propulsion technologies that cannot be reasonably achieved within the cost or schedule constraints of mission development timelines. Specifically, achieving technology readiness level (TRL) 6 prior to preliminary design review (PDR). The goal of ISPT is to develop products that realize near-term and mid-term benefits. Therefore, ISPT primarily focuses on technologies in the mid TRL range (TRL 3-6+ range) that have a reasonable chance of reaching maturity in 4-6 years provided adequate development resources. The project strongly emphasizes developing propulsion products for NASA flight missions.

Since 2001, the In-Space Propulsion Technology (ISPT) program developed and delivered in-space propulsion technologies that enables and/or benefits near and mid-term NASA robotic science missions by significantly reducing cost, mass, and/or travel times. ISPT technologies will help deliver spacecraft to SMD's destinations of interest. In 2009, the ISPT program was tasked to start development of propulsion technologies that would enable future sample return missions. 
This paper provides a brief overview of the In-Space Propulsion Technology (ISPT) program, describing the planning and development status of in-space propulsion technologies in the areas of electric propulsion for Earth Return Vehicles (ERV) and Discovery-class missions, planetary ascent vehicles, Earth return vehicles, other advanced propulsion technologies, and mission/systems analysis. These in-space propulsion technologies are applicable, and potentially enabling for future NASA flagship and sample return missions currently under consideration, as well as having broad applicability to future Discovery and New Frontiers mission solicitations.

\section{TeChNOLOGY DEVELOPMENT OVERVIEW}

ISPT emphasizes technology development with mission pull. In the near-term the ISPT goal will be to develop propulsion technologies for sample return and Discoveryclass missions. Sample return missions could be quite varied, from collecting and bringing back samples of comets or asteroids, to soil, rocks, or atmosphere from planets or moons.

Given this new focus, the future technology development areas for ISPT are:

(1) Sample Return Propulsion (SRP)

(2) Planetary Ascent Vehicles (PAV)

(3) Multi-mission technologies for Earth Entry Vehicles (MMEEV)

(4) Systems/mission analysis and tools that focuses on sample return propulsion.

Sample Return Propulsion is further broken down into:

(1) Electric propulsion for sample return and low cost Discovery-class missions

(5) Propulsion systems for Earth Return Vehicles (ERV) including transfer stages to the destination

(6) Low TRL advanced propulsion technologies.

The SRP effort will continue work on HIVHAC thruster development in FY2010 and then transition into developing a HIVHAC system under future Electric Propulsion for sample return (ERV and transfer stages) and low-cost missions. Previous work on the lightweight propellant-tanks will continue under advanced propulsion technologies for sample return with direct applicability to a Mars Sample Return (MSR) mission and with general applicability to all future planetary spacecraft.

ISPT's earlier Aerocapture efforts will merge with previous work related to Earth Entry Vehicles and transitions into the future multi-mission technologies for Earth Entry Vehicles (MMEEV). The Planetary Ascent Vehicles (PAV)/Mars Ascent Vehicle (MAV) is a new development area to ISPT, but builds upon and leverages the past MAV analysis and technology developments from the Mars Technology Program (MTP) and previous MSR studies.

The systems analysis technology area performed numerous mission and system studies to guide technology investments and quantify the return on investment. Recent focus of the systems analysis area is on developing reference missions and conducting mission sensitivities to assist technology gap identification or application.

\section{Electric Propulsion for SAMPle RETURN AND DISCOVERY-CLASS MISSIONS}

ISPT is investing in Sample Return Propulsion technologies for applications such as Earth-Return Vehicles for large and small bodies. The first example leverages the development of a High-Voltage Hall Accelerator (HIVHAC) Hall thruster into a lower-cost electric propulsion system. [1] HIVHAC is the first NASA electric propulsion thruster specifically designed as a low-cost electric propulsion option. It targets Discovery and New Frontiers missions and smaller mission classes. The HIVHAC thruster does not provide as high a maximum specific impulse as NEXT, but the higher thrustto-power and lower power requirements are suited for the demands of some Discovery-class missions and sample return applications. Advancements in the HIVHAC thruster include a large throttle range from $0.3-3.5 \mathrm{~kW}$ allowing for a low power operation. It results in the potential for smaller solar arrays at cost savings, and a long-life capability to allow for greater total impulse with fewer thrusters. It allows for cost benefits with less complex systems.

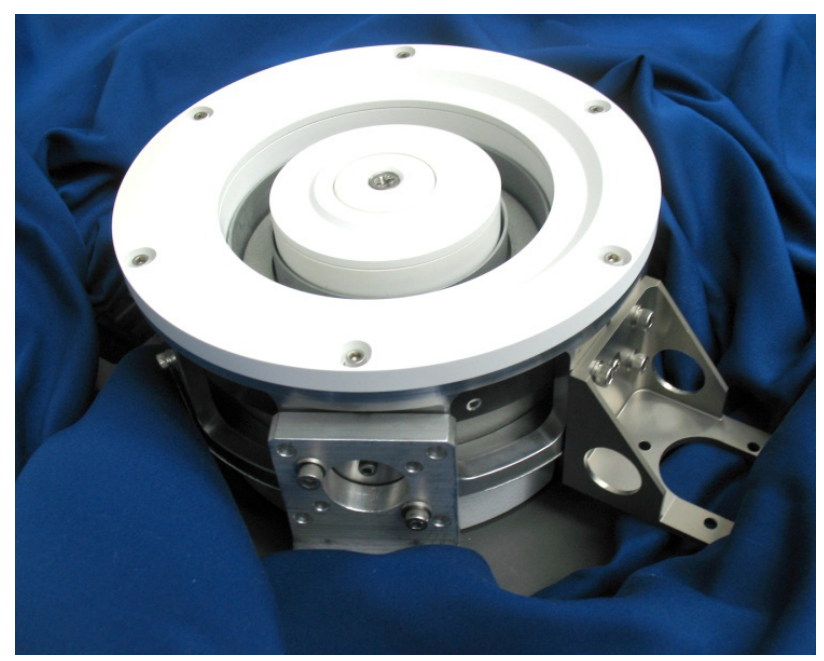

Figure 1 - HIVHAC Thruster Engineering Model

Wear tests of the NASA-103M.XL thruster validated and demonstrated the patented life extending innovation as a means to mitigate discharge channel erosion as a life limiting mechanism in Hall thrusters. Test priorities then focused on the wear test of the laboratory thruster to validate the lifetime extending innovation to demonstrate throughput capabilities of the design. The thruster, shown in 
Figure 1, operated in excess of 4700 hours ( $100 \mathrm{~kg}$ of xenon throughput).

Components for two Engineering Model (EM) thrusters were fabricated. To date one of the thrusters has been assembled for tests. Preliminary performance mapping of the EM thruster at various operating conditions was performed at NASA Glenn Research Center (GRC). [2] In the future, the test sequence will include performance acceptance tests, environmental tests and a long duration test in FY11 and FY12. Current plans include the design, fabrication and assembly of a full Hall propulsion system, but are pending final approval to proceed.

In addition to the thruster development, the HIVHAC project is evaluating power processing unit (PPU) and xenon feed system XFS development options that were sponsored by other projects but can apply directly to a HIVHAC system. The goal is to advance the TRL level of a HIVHAC Hall thruster propulsion system to level 6 in preparation for a first flight.

The functional requirements of a HIVHAC PPU are operation over a power throttling range of 300 to $3,800 \mathrm{~W}$, over a range of output voltages between 200 and $700 \mathrm{~V}$, and output currents between 1.4 and $5 \mathrm{~A}$ as the input varies over a range of 80 to $160 \mathrm{~V}$. A Performance map across these demanding conditions was generated for one candidate option. [3] Beyond conventional feed system options, one option for feed systems that was demonstrated with the Hall thruster is the VACCO advanced xenon feed system.

The ISPT project addresses the need for low-cost electric propulsion options. Studies [4] indicate that a low-power Hall thruster is cost enabling, and enhances performance. Initial studies compared the HIVHAC thruster to State of the Art (SOA) systems for Near-Earth Object (NEO) sample returns, comet rendezvous, and the Dawn science mission. The HIVHAC thruster is expected to have both a greater throughput capability and a lower recurring cost than the SOA NSTAR thruster.

For the NEO mission evaluated, the HIVHAC thruster system delivered over 30 percent more mass than the NSTAR system. The performance increase accompanied a cost savings of approximately 25 percent over the SOA NASA Solar electric propulsion Technology Application Readiness (NSTAR) system. The Dawn mission was evaluated, and the expected HIVHAC Hall thruster delivered approximately 14 percent more mass at substantially lower cost than SOA, or decreasing the solar array provided equivalent performance at even greater mission cost savings. [5]

\section{Planetary Ascent Vehicle (PAV)}

For many years, NASA and the science community asked for a Mars Sample Return (MSR) mission. There were numerous studies to evaluate MSR mission architectures, technology needs and development plans, and top-level requirements. Because of the challenges, technologically and financially, of the MSR mission, NASA initiated a study to look at MSR propulsion technologies through the In-Space Propulsion Technology (ISPT) project office. [6] The objective of the ISPT project is to develop propulsion technologies that enhance or enable NASA science missions for the planetary science division by increasing performance while reducing cost, risk, and/or trip length. The largest propulsion risk element of the MSR mission is the Mars Ascent Vehicle (MAV).

The development of a major subsystem of the Mars Sample Return mission requires a direct and in-depth analysis on technology sensitivities to the overall MSR architecture and the mission's concept of operations (CONOPS). The MSR architecture dictates the physical and thermal environments, power requirements, and system interface of the MAV system.

The current architecture (Figure 2) for the MSR lander is to use the Mars Science Laboratory (MSL) entry, descent, and landing (EDL) system. The MSL EDL requires minor modifications such as a larger parachute, additional propellant, and Composite Overwrap Pressure Vessel (COPV) propellant tanks to accommodate a lander that will slightly exceed the lander mass of the MSL rover. Using the MSL sky crane concept places restrictions on the MAV system options.

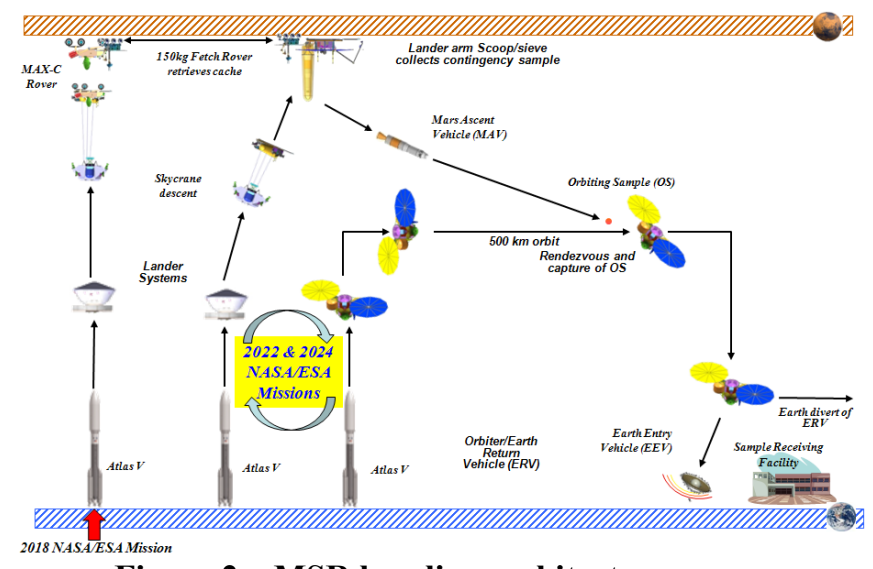

Figure 2 - MSR baseline architecture

Beyond the limitations of the EDL system, the MAV (Figure 3) has specific requirements to deliver the orbiting sample (OS) into an orbit suitable for the Earth Return Vehicle (ERV). The basic requirements include:

- $500 \mathrm{~km}+/-100 \mathrm{~km}$ circular orbit

- $45^{\circ}+/-0.2^{\circ}$ inclination

- Ability to launch from $+/-30^{\circ}$ latitudes

- Accommodate $\sim 5 \mathrm{~kg}, 16 \mathrm{~cm}$ diameter payload

- Continuous telemetry

- Storage for 90 Sols, potentially up to one Martian year 


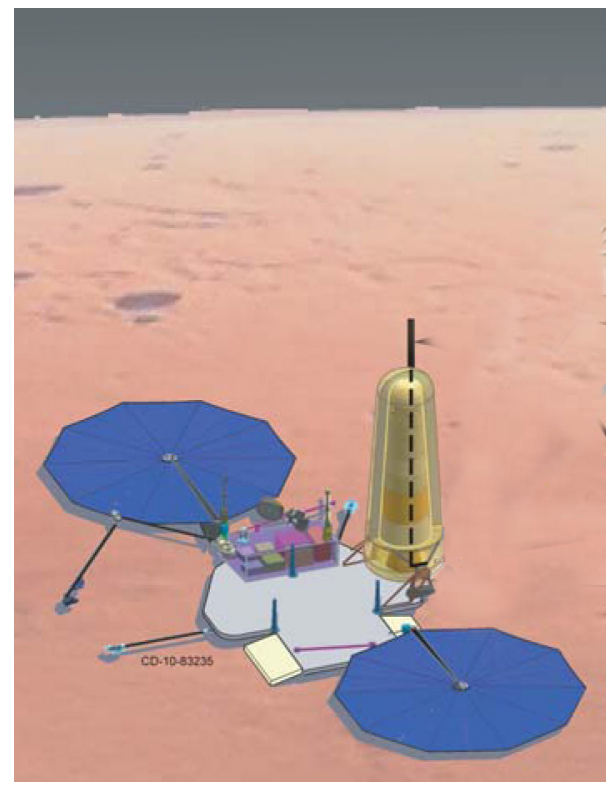

Figure 3 - MAV Launch Platform

The following technology development strategy is predecisional and is an approach under consideration. The strategy for technology development is the employment of an Integrated Product Development Team (IPDT) with updates as necessary to a technology steering community and host workshops as appropriate. The IPDT consists of members from ISPT project office, the Mars Exploration Program at the Jet Propulsion Laboratory (JPL) for intimate knowledge of the system interfaces, requirements, and sensitivities to the overall MSR mission, and NASA launch vehicle system design and test support. Management of the subsystem and system development is based in NASA's ISPT project with lead systems engineering support to maintain interface controls and guide system integration activities.

Potential MAV propulsion concepts range from solid, liquid, and hybrid systems with state-of-the-art or advanced propellants, and numerous subsystem architectures. These various concepts all have gross lift-off mass (GLOM) implications to the MAV system. Vehicle sensitivities were established for the MAV through the minimization of the GLOM for a wide range of launch conditions, vehicle performance, and final payload orbit.

Using the payload, dry masses, thrust and $\mathrm{I}_{\mathrm{sp}}$ assumptions listed in Table 1 and Table 2, an OTIS model was developed at NASA's Glenn Research Center (GRC) along with a POST model by the team at NASA's Marshall Space Flight Center (MSFC). OTIS is the Optimal Trajectories by Implicit Simulation program and POST is the Program to Optimize Simulated Trajectories; both commonly used for launch vehicle performance analyses. The existing TSTO baseline mission and performance parameters were used as defined in Table 1 and 2.
Table 1 - TSTO MAV Baseline Masses

\begin{tabular}{|l|c|l|}
\hline \multicolumn{1}{|c|}{ MAV Element } & Mass(kg) & \multicolumn{1}{|c|}{ Description } \\
\hline Stage 1 Dry & 27.7 & $\begin{array}{l}\text { Motor casing, nozzle } \\
\text { and interstage. }\end{array}$ \\
\hline Stage 1 Propellant & 158.6 & $\begin{array}{l}\text { Solid propellant } \\
\text { stretched Star 17. }\end{array}$ \\
\hline Stage 2 Dry & 38.4 & $\begin{array}{l}\text { Motor casing, } \\
\text { avionics, payload } \\
\text { attach structure. }\end{array}$ \\
\hline Stage 2 Propellant & 34.7 & $\begin{array}{l}\text { Solid propellant Star } \\
\text { 13B. }\end{array}$ \\
\hline Payload Fairing & 3.1 & $\begin{array}{l}\text { PLF jettisoned with } \\
\text { first stage @ 200km. }\end{array}$ \\
\hline Payload & 5.0 & Sample and Container \\
\hline
\end{tabular}

Table 2 - TSTO MAV Baseline Thrust and $I_{s p}$

\begin{tabular}{|l|l|}
\hline Engine Parameter & Value \\
\hline Stage 1 Thrust (N) & 21576.8 \\
\hline Stage 1 Isp (s) & 285.7 \\
\hline Stage 1 Exit Area $\left(\mathrm{m}^{2}\right)$ & 0.032 \\
\hline Stage 2 Thrust (N) & 6318.9 \\
\hline Stage 2 Isp (s) & 285.5 \\
\hline Stage 2 Exit Area $\left(\mathrm{m}^{2}\right)$ & 0.0093 \\
\hline
\end{tabular}

A large number of trades were completed for various launch inclinations, elevations, and azimuths in addition to propulsion system trades of thrust and $\mathrm{I}_{\mathrm{sp}}$, various system mass assumptions, and various final orbits. A notional launch configuration of the MAV prior to launch is illustrated in Figure 4. An example trade of sensitivity of the MAV GLOM to launch site inclination is shown in Figure 5. The detailed trades are presented in Ref. [7] and will be available as a NASA Technical Memorandum. 


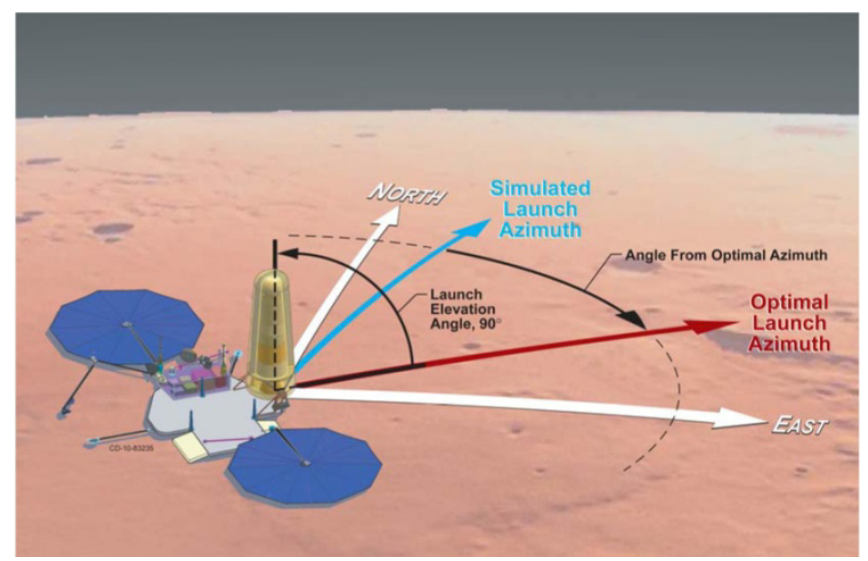

Figure 4 - MAV GLOM vs. launch inclination

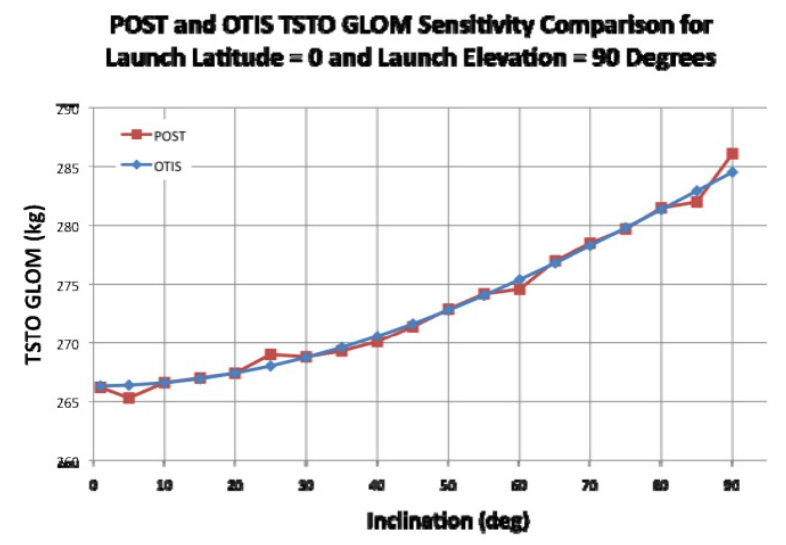

Figure 5 - MAV GLOM vs. Launch inclination

Through the NASA Research Announcement (NRA) process, the ISPT project solicited MAV system designs and plans to initiate propulsion system development. The NRA was released in February 2010 with proposals received in May, 2010. Some of the proposed technologies have potential to converge within the existing MSL EDL capabilities while other options may be enabled by enhancements to the EDL system. Multiple contractors were selected to proceed in October of 2010. Awards are expected in early FY11. During the NRA efforts, the contractors will complete Principal Investigator (PI) led collaborative engineering designs of the MAV with contract options to begin the required technology development.

The ISPT project also completed a baseline concept design of the MAV for an independent comparison to the contractor designs. The baseline design is a two-stage solid propulsion system with a gross lift-off mass of $300 \mathrm{~kg}$ assuming 30 percent margin. The baseline MAV concept design is shown in Figure 6. The baseline design is predecisional and for understanding design trades and sensitivities; it does not represent any concept selection.

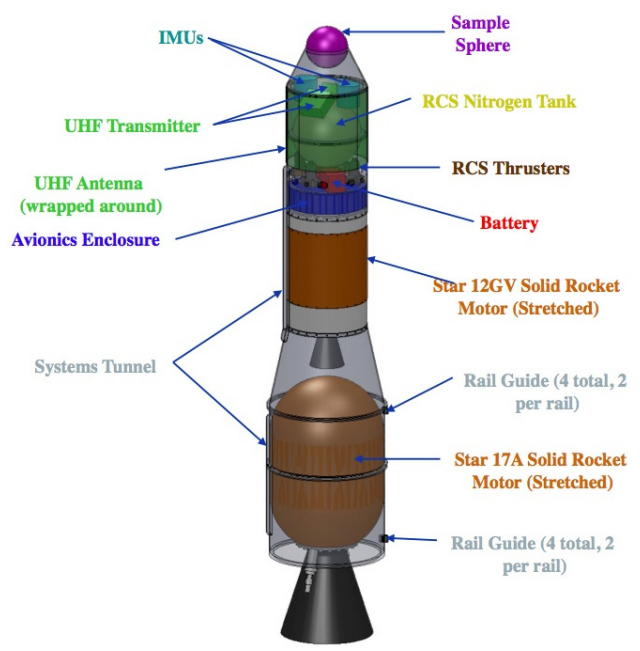

Figure 6 - Baseline MAV Concept Design

\section{Propulsion Component Technologies}

ISPT also invests in the evolution of subcomponent technologies that offer significant performance improvements without increasing system level risk. Two component technologies currently receiving investments are xenon feed systems and Ultra-Light Tank Technology (ULTT).

The ISPT project has invested in a highly reliable, lightweight, and low-cost xenon flow control system. [8] A follow-on contract was awarded to VACCO as a joint ISPT and Air Force effort to qualify a Hall system module. This module would significantly reduce the cost, mass, and volume of a Hall thruster xenon control system while maintaining high reliability and decreasing tank residuals. The improvements are more than a factor of three compared to standard regulators and proportional flow control valves. A conceptual drawing of the Hall module is shown in Figure 7. 


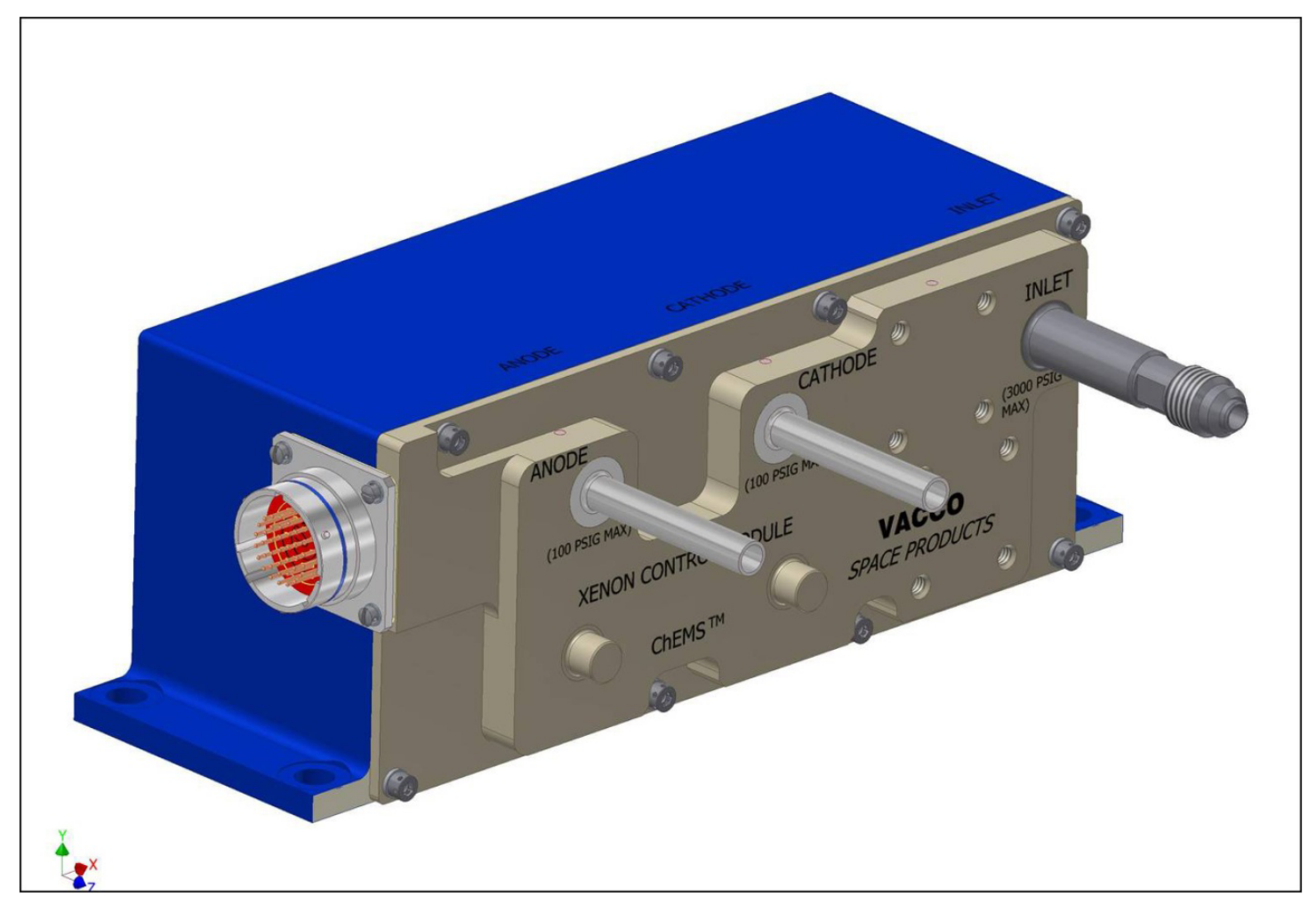

Figure 7 - VACCO Xenon Flow Control Module

The ISPT project has also invested in ultra-light-weight tank technology previously. The ULTT efforts in the past have focused on manufacturability and non-destructive evaluation of the lightweight tanks. The ISPT project is currently planning to develop and qualify positive expulsive ultra light-weight tanks specifically for the MSL SkyCrane. These tanks can offer mass savings on the order of 24-30kg, dependent on the final tank wall thickness, and therefore increase the landed mass capability of SkyCrane for a relatively low cost per $\mathrm{kg}$. The SkyCrane EDL system is planned for the 2018 NASA/European Space Agency Mars mission and for the MSR lander. Both are highly mass constrained. The MSL SkyCrane, with large propellant tanks, is shown in Figure 8. While the tanks will be qualified for the SkyCrane application, the technology will be broadly applicable for a wide range of future science missions.

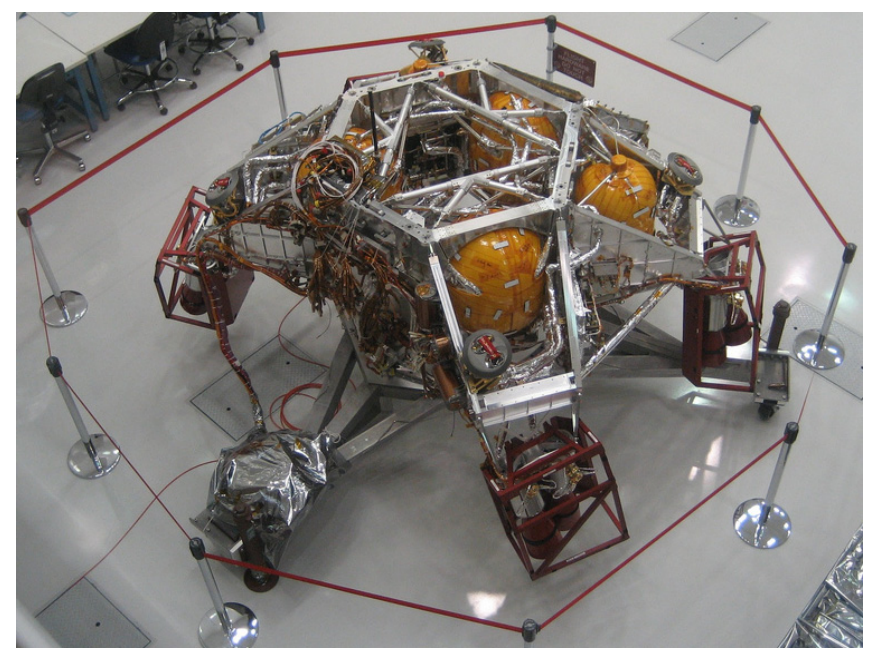

Figure 8 - MSL SkyCrane 


\section{Multi-Mission EARTh Entry Vehicle (MMEEV)}

The Multi-Mission Earth Entry Vehicle (MMEEV) is a flexible design concept which can be optimized or tailored by any sample return mission, including lunar, asteroid, comet, and planetary (e.g. Mars), to meet that mission's specific requirements. Based on the Mars Sample Return (MSR) Earth Entry Vehicle (EEV) design, which due to planetary protection requirements, is designed to be the most reliable space vehicle ever flown, the MMEEV concept provides a logical foundation by which any sample return mission can build upon in optimizing an EEV design which meets their specific needs. By leveraging common design elements, this approach can significantly reduce the risk and associated cost in development across all sample return missions, while also providing significant feedforward risk reduction in the form of technology development, testing, and even flight experience, for an eventual MSR implementation.

The current MMEEV parametric configuration and mass model, developed for a range of vehicle parameters, including vehicle diameter and payload mass/size, is presented in Figure 9 (basic vehicle architecture) and Table 3 (range of parametric variables). Engineering estimates of MMEEV vehicle and trajectory performance are generated using the NASA Langley Research Center's 6-DOF simulation software, Program to Optimize Simulated Trajectories (POST2). Fully integrated with POST2 are MMEEV specific models, including vehicle mass properties, aerodynamics, aerothermodynamics, Thermal Protection System (TPS) thickness/sizing, and a simplified 1-D impact analysis. Preliminary estimates for heat rates, heat loads, impact environments, and other vehicle and trajectory performance characteristics are provided across the MMEEV design trade space, which includes vehicle configuration and payload considerations, as well as a broad range of likely sample return mission entry conditions (e.g. entry velocity and entry flight path angle). Since each individual sample return mission may have a unique set of performance metrics of highest interest, the goal is to provide a qualitative performance comparison across the specified trade space. From this, each sample return mission can select the most desirable design point from which to begin a more optimized design.

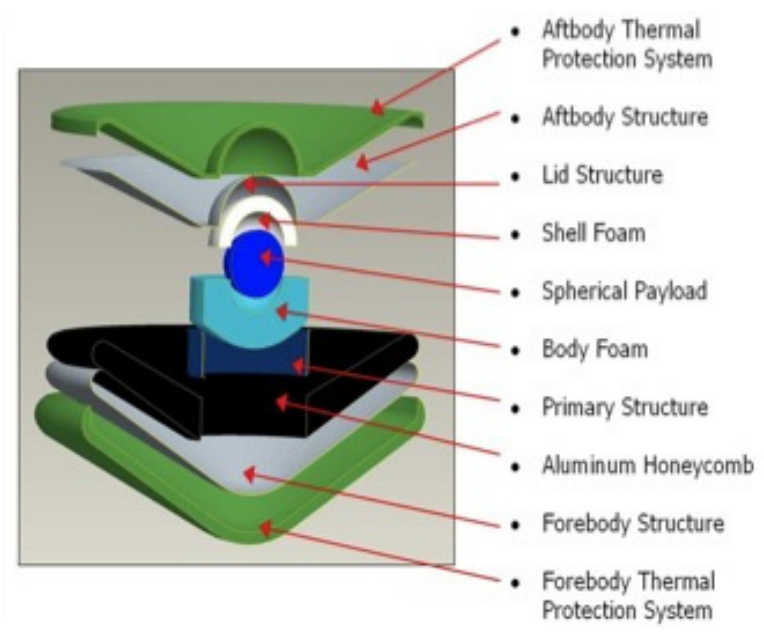

Figure 9 - Basic MMEEV architecture

Table 3 - MMEEV parametric variable

\begin{tabular}{|l|l|}
\hline Parametric Variable & Range \\
\hline Payload & 5 to $30 \mathrm{~kg}$ \\
\hline Vehicle Diameter & 0.5 to $2.5 \mathrm{~m}$ \\
\hline \multicolumn{1}{|c|}{ Inertial Entry Velocity } & 10 to $16 \mathrm{~km} / \mathrm{s}$ \\
\hline $\begin{array}{l}\text { Inertial Entry Flight Path } \\
\text { Angle }\end{array}$ & $-5^{\circ}$ to $-25^{\circ}$ \\
\hline
\end{tabular}

Continued development of the MMEEV models is planned to include: more sophisticated parametric configuration, including payload accommodation, models; higher fidelity impact dynamics model (e.g. finite-element model); updated aerodynamics models based on ground (e.g. wind tunnel and ballistic range) testing as well as Computational Fluid Dynamics (CFD) analysis; and high fidelity TPS mass/thickness sizing models for additional candidate TPS materials. MMEEV performance studies will also continue, with the eventual integration of the MMEEV models into an EDL "Quicklook" Tool, a prototype EDL analysis tool, originally developed in support of ISPT aerocapture studies, and currently being developed to support mission studies to any celestial body with an atmosphere.

Detailed studies show that to meet the stringent containment requirements for a Mars sample return mission, the MMEEV should possess particular design attributes. First, the vehicle aerodynamics must be very well understood. This means utilizing a shape with extensive analysis, testing, and flight experience. The vehicle aerodynamics must also be "self-righting," so it will quickly stabilize itself in a heatshield-forward orientation if the release from the ERV, a micrometeoroid impact, or some other anomaly, cause it to enter the atmosphere in any other orientation. Second, the heat shield TPS needs to be robust enough to ensure a high level of reliability for both nominal and offnominal (such as MMOD impacts) environments. Third, the 
MMEEV has no parachute or other deployable drag device, since the reliability of such a device is several orders of magnitude less than the level likely required (i.e. the capsule would still need to be designed to survive and safely contain the sample after an Earth impact in the event of a failure of the drag device).

The biggest challenge for any space vehicle, including the MMEEV, is to adequately prove the reliability of the components, subsystems, and the flight system as a whole. The current estimate to develop the EEV technology for MSR to TRL-6 is approximately $\$ 41$ million. This does not include a dedicated flight test, which many experts agree is needed to achieve the $10^{-6}$ probability of failure, since the entry flight environment cannot be replicated in groundbased facilities. This is a fairly expensive flight test due to the high entry velocities that are required. One way to achieve a flight validation for little extra cost to NASA is to use the MMEEV design concept, or at least the major components of the design, in sample return missions likely to fly prior to MSR, such as New Frontiers or Discovery. NASA Headquarters managers and the In-Space Propulsion Technology (ISPT) team are pursuing this approach, but currently there are no manifested missions that are planning to use an MSR EEV design.

\section{SyStems/Mission ANALYSIS}

Systems analysis is used during all phases of any propulsion hardware development. The systems analysis area serves two primary functions:

(1) to help define the requirements for new technology development and the figures of merit to prioritize the return on investment,

(2) to develop new tools to easily and accurately determine the mission benefits of new propulsion technologies allowing a more rapid infusion of the propulsion products.

Systems analysis is critical prior to investing in technology development. In today's environment, advanced technology must maintain its relevance through mission pull. Recent and ongoing systems analysis studies include Mars Earth Return Vehicle (MERV), [9] main-belt asteroid sample return (Figure 10), [10] Discovery class mission cost viability, [11] and the MAV sensitivity trades.

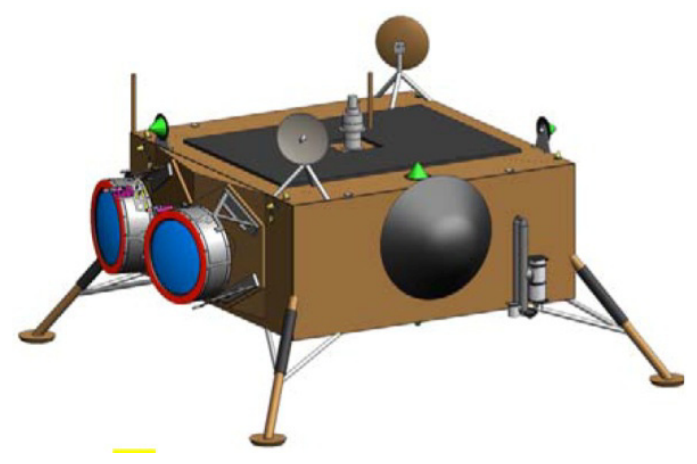

Figure 10 - Notional Main-belt Asteroid Sample Return spacecraft (shown without solar array)

The second focus of the systems analysis project area is the development and maintenance of tools for the mission and systems analyses. Improved and updated tools are critical to clearly understand and quantify mission and system level impacts of advanced propulsion technologies. Having a common set of tools increases confidence in the benefit of ISPT products; both for mission planners as well as for potential proposal reviewers.

The ISPT program has made significant investments in trajectory optimization, chemical system sizing, and aerocapture "Quicklook" assessment tools. The ISPT program will continue to update these programs and make them freely available to the user community. A list of ISPT tools and instructions to request these tools can be found on the ISPT web site. [12]

\section{Conclusion and Future Plans}

The future focus areas for ISPT are propulsion systems for sample return missions. Activity in these technology development areas continues in 2010 and starts increasing in 2011. The direction focuses on: 1) Planetary Ascent Vehicles; 2) multi-mission technologies for Earth Entry Vehicles required for sample return missions; and 3) electric and chemical propulsion for Earth Return Vehicles, transfer stages, and low cost Discovery-class missions. These sample return missions are inherently propulsion intensive.

Several of the earlier ISPT technology areas may also be involved in a single sample return mission. The mission may use Electric Propulsion for transfer to, and possibly back from, the destination. Chemical propulsion may be utilized for the ascent and descent to the surface. Aeroshells may be used for Earth re-entry and an aerocapture maneuver used to capture at the destination.

Future sample return missions of interest for NASA and the science community, and those that are yet to be conceived, continue to demand propulsion systems with increasing performance and lower cost. This paper addresses how the ISPT project is starting to develop propulsion technologies 
for NASA's future sample return missions. While the budget is tight for the next few years, the future is bright.

\section{ACKNOWLEDGMENTS}

The results and findings presented here are based on work funded by the National Aeronautics and Space Administration (NASA), Science Mission Directorate (SMD). ISPT implements the project through task agreements with NASA centers, contracts with industry, and via grants with academic institutions. Implementing NASA centers include Ames Research Center (ARC), Glenn Research Center (GRC), Jet Propulsion Laboratory (JPL), Langley Research Center (LaRC), and the Marshall Space Flight Center (MSFC). There are also numerous industry partners in the development of the ISPT products. The authors acknowledge the technical achievements by the respective NASA and contractor teams and the contributions of the respective technology area project managers. In addition, many thanks to Linda Nero for her administrative, editorial, and clerical support of this paper.

\section{REFERENCES}

[1] Kamhawi, H., "Overview of the High voltage Hall Accelerator Project," AIAA-2009-5282, 45th AIAA/ASME/SAE/ASEE Joint Propulsion Conference and Exhibit, Denver, CO, August 2009.

[2] Kamhawi, H., et al., "High Voltage Hall Accelerator Project Overview", IEPC-2009-092, Proceedings of the $31^{\text {st }}$ International Electric Propulsion Conference, Ann Arbor, MI, September 2009.

[3] Kamhawi, H., "Overview of the High voltage Hall Accelerator Project," AIAA-2009-5282, 45th AIAA/ASME/SAE/ASEE Joint Propulsion Conference and Exhibit, Denver, CO, August 2009.

[4] Cupples, M., Coverstone, V., and Woo, B., "Applications of Solar Electric Propulsion to a Comet Surface Sample Return Mission," AIAA-2004-3804, 40th AIAA/ASME/SAE/ASEE Joint Propulsion Conference and Exhibit, Fort Lauderdale, GL, July, 2004.

[5] Oh, D.,"Evaluation of Solar Electric Propulsion Technologies for Discovery Class Missions," AIAA2005-4270, 41st AIAA/ASME/SAE/ASEE Joint Propulsion Conference \& Exhibit, Tucson, AZ, July, 2005.

[6] Dankanich, J. W., "Mars Ascent Vehicle Technology Planning," 2009 IEEE Aerospace Conference, Big Sky, MT, March 2009.
[7] Dux, I. J., Huwaldt, J. A., McKamey, R. S., and Dankanich, J. W., "Mars Ascent Vehicle Gross Lift-off Mass Sensitivities for Robotic Mars Sample Return, “ 2011 IEEE Aerospace Conference, Big Sky, MT., March 2011

[8] Dankanich, J. W., Cardin, J., Dien, A., Kamhawi, H., Netwall, C. J., and Osborn, M., "Advanced Xenon Feed System (AXFS) Development and Hot-fire Testing," AIAA 2009-4910, 45th AIAA Joint Propulsion Conference, Denver, CO, August 2-5, 2009.

[9] Dankanich, J. W., Burke, L. M., and Hemminger, J. A., "Mars Sample Return Orbiter / Earth Return Vehicle Technology Needs and Mission Risk Assessment," 2010 IEEE Aerospace Conference, Big Sky, MT, March 2010.

[10] Dankanich, J. W., Landau, D. L., Martini, M. C., Oleson, S. R., and Rivkin, A., "Main Belt Asteroid Sample Return Mission Design," AIAA 2010-7015, 46 ${ }^{\text {th }}$ Joint Propulsion Conference, Nashville, TN, July 25-28, 2010.

[11] Dankanich, J. W., Drexler, J. A., and Oleson, S. R., "Electric Propulsion Mission Viability within the Discovery Class Cost Cap" AIAA 2010-6776, 46 ${ }^{\text {th }}$ Joint Propulsion Conference, Nashville, TN, July 25-28, 2010.

[12] NASA In-Space Propulsion Technology (ISPT) Web site http://spaceflightsystems.grc.nasa.gov/Advanced/Science Project/ISPT/LTTT/. 


\section{BIOGRAPHIES}

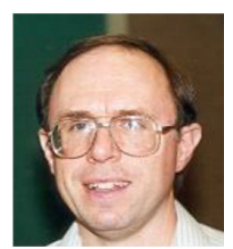

David Anderson is a project manager in the Science Project Office at the NASA Glenn Research Center (GRC). He is currently the Acting Project Manager for the In-Space Propulsion Technology (ISPT) project, and is the SBIR Spacecraft and Platform Subsystems Topic Manager. Formerly, he managed the advanced Radioisotope Power System (RPS) efforts at NASA GRC, was active with new business development and proposal development activities. He worked in GRC's Systems Management Office, where he was involved in project management oversight activities and led or was involved in several Center and NASA-wide program/project management process improvement teams or activities. He has a B.S. in Aerospace Engineering from the University of Cincinnati and an M.S. in Engineering Management from the Cleveland State University.

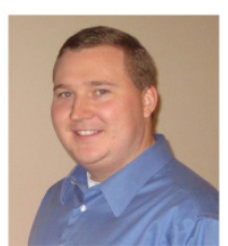

John Dankanich is a Gray Research contractor to the NASA Glenn Research Center. He is the electric propulsion lead systems engineer for the ISPT project. He also serves as a mission and systems analyst for the ISPT project and the Glenn Research Center. John has expertise in mission and systems analyses, electric propulsion systems, and trajectory optimization. He supported propulsion system development, Mars ascent vehicle design, lunar lander guidance simulations, planetary defense studies, and advanced propulsion design and testing. John has a B.S. in Physics and Aerospace Engineering and an M.S. in Aerospace Engineering from Purdue University.

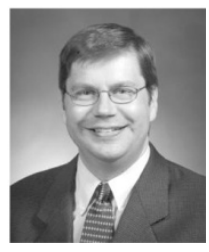

Eric Pencil is Propulsion Projects Area Manager for the In-Space Propulsion Technology Office at NASA Glenn Research Center. He is responsible for the management and execution of the electric propulsion development tasks for NASA Science missions. Previously he worked as a project/research engineer in the electric propulsion research group in which he worked on various electric propulsion technologies at varying stages of maturity from basic research to flight hardware.

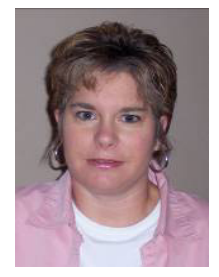

Michelle Munk has been a NASA employee for nearly 20 years, first at the Johnson Space Center, then at the Langley Research Center. She has been involved in Mars advanced mission studies for many years, both robotic and human, contributing interplanetary trajectory analysis and entry and descent analysis. She managed the delivery of International Space Station hardware, and was on the Mars Odyssey aerobraking operations team. In 2002, Ms. Munk accepted a detail assignment to become the Lead Engineer for Aerocapture Technology Development under In-Space Propulsion at Marshall Space Flight Center. She managed the technical work of ISP Aerocapture for nearly five years before becoming the Project Area Manager and returning to Langley in 2007. Ms. Munk is also involved in the Mars Science Laboratory Entry, Descent and Landing Instrumentation (MEDLI) project and contributes to other NASA projects developing entry system technologies. She has a BSAE from Virginia Tech and completed graduate coursework at the University of Houston.

David Hahne is currently managing the Multi-Mission Earth Entry Vehicle activities for the In-Space Propulsion Technology project. A NASA-Langley employee for nearly 30 years, his technical background is in vehicle dynamics, stability, and control. He started managing technology $R \& D$ efforts in the 90's for the High Speed Research Program and has since been part of the management team of several other government-industry partnerships developing technology ranging from easy-to-fly general aviation aircraft to fuel efficient commercial transports. He has a BS in Aerospace Engineering from Virginia Tech and an MS in Aeronautics from George Washington University.

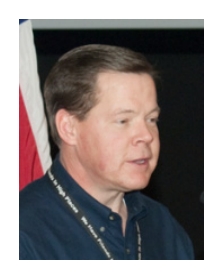

Todd Peterson is a project manager in the Advanced Capabilities Project Office at the NASA Glenn Research Center (GRC). With over 26 years of space flight project experience at NASA GRC, he has extensive propulsion, power and communication system project management experience in human and robotic space flight projects (Space Station, Shuttle/Mir, Deep Space-1, Earth Observer-1, Lunar Reconnaissance Orbiter) and development projects (electric propulsion, chemical propulsion, photovoltaic \& dynamic power systems, microgravity research). He has a B.S. in Mechanical Engineering from the University of Akron and an M.S. in Mechanical Engineering from Cleveland State University. 